\title{
Can be Grandmother as Child's Daytime Caregiver a Risk Factor for Higher Caries Experience in Early Childhood? A Retrospective Study
}

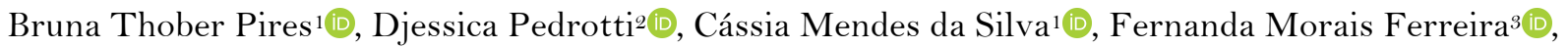 \\ Márcia Figueiredo Cançado ${ }^{1}$, Tathiane Larissa Lenzi[D
}

\begin{abstract}
${ }^{1}$ Department of Surgery and Orthopedics, Faculty of Dentistry, Federal University of Rio Grande do Sul, Porto Alegre, RS, Brazil.

2Post-Graduate Program in Pediatric Dentistry, Faculty of Dentistry, Federal University of Rio Grande do Sul, Porto Alegre, RS, Brazil.

${ }^{3}$ Faculty of Dentistry, Department of Pediatric Dentistry and Orthodontics, Federal University of Minas Gerais, Belo Horizonte, MG, Brazil.
\end{abstract}

Author to whom correspondence should be addressed: Tathiane L. Lenzi, Post-Graduate Program in Pediatric Dentistry, Faculty of Dentistry, Federal University of Rio Grande do Sul, Ramiro Barcelos 2492, Santa Cecília, Porto Alegre, RS, Brazil.90035-003. Phone: +55 5133085493. E-mail: tathilenzi@hotmail.com.

Academic Editor: Burak Buldur

Received: 17 March 2020 / Accepted: 14 May 2020 / Published: 31 July 2020

How to cite this article: Pires BT, Pedrotti D, Silva CM, Ferreira FM, Cançado MF, Lenzi TL. Can be grandmother as child's daytime caregiver a risk factor for higher caries experience in early childhood? A retrospective study. Pesqui Bras Odontopediatria Clín Integr. 2020; 20:e0054. https://doi.org/10.1590/pboci.2020.150

\begin{abstract}
Objective: To investigate the association between child's daytime caring person and risk for higher early childhood caries (ECC) experience. Material and Methods: The sample consisted of all clinical records (census) of children (0-3 years old) attended in a public dental clinic, which contained information about caries experience and child's daytime caring person (mother, grandmother or others). Caries experience was dichotomized as $\mathrm{dmft} \leq 2$ or $\mathrm{dmft}>2$. Data were analyzed by the chi-square $(\alpha=0.05)$. Binary logistic regression models were built. Results: From a total of 310 children, $19 \%$ of children had the grandmother as daytime caring person. There was no association between child's daytime caring person and caries experience $(\mathrm{p}=0.32)$. Logistic regression analysis showed that low daytime caregiver schooling (OR: 5.76 95\%CI 1.18-28.18; $\mathrm{p}=0.02)$ and child's age (OR: $1.1495 \% \mathrm{CI} 1.09-1.19 ; \mathrm{p}=0.00)$ were risk factors, and breastfeeding duration (> 9 months - OR: $0.3895 \%$ CI $0.21-0.68 ; \mathrm{p}=0.00$ ), no nocturnal feeding (OR: 0.50 95\% CI 0.27-0.91; $\mathrm{p}=0.02$ ), and absence of sugar consumption between main meals (OR: $0.5095 \%$ CI $0.28-$ $0.89 ; \mathrm{p}=0.02)$ were protection factors for ECC. Conclusion: A higher caries experience in early childhood is not associated to child's daytime caring person. On the other hand, the higher caries experience is associated with low caregiver schooling and older children.
\end{abstract}

Keywords: Dental Caries; Child; Tooth, Deciduous; Caregivers. 


\section{Introduction}

Early childhood caries (ECC) is defined as the presence of one or more decayed (non cavitated or cavitated lesions), missing or filled (due to caries) surfaces, in any primary tooth of a child under six years of age [1,2]. ECC still affects more than 600 million children worldwide and remains largely untreated [Q], negatively impacting on oral health-related quality of life of children and their families [3,4].

Dental caries is determined by biological, behavioral, and psychosocial factors linked to an individual's environment [5]. ECC, like other forms of caries, is considered to be a biofilm-mediated, sugar-driven, multifactorial, dynamic disease that results in the imbalance of demineralization and remineralization of dental hard tissues [6]. Baby bottle and breastfeeding in the first year of age, especially if frequent and/or nocturnal, are related with ECC [7]. Furthermore, early childhood is a crucial time for the development of eating behaviors and food preferences. It has been evidenced that the introduction of highly sweetened foods and drinks beyond 12 months is strongly associated with caries incidence in subsequent years [8].

Although daily decisions about child nutrition, education, and health are responsibility of parents [9], often, children spend most of their day in day care or under care of baby-sitters, grandparents, or other relatives. Thus, children's oral health practices are influenced by knowledge and habits of their caregivers [10]. It has been shown that the caregiver's low education level and attendance in preschool were associated with caries experience of children [11].

An increasingly prevalent family constellation is a home headed by a grandmother who is raising grandchildren [12]. It may be related not only to higher life expectancy, but also to role exercised by grandparents in many situations, such as adolescent motherhood, divorce or professional activities of their offspring [12]. Grandparents' cultural aspects, such as their beliefs may influence on children's oral health. Grandmothers may utilize the food as a reward, to regulate children's emotions and as a tool to express their love [13]. In this sense, children with a grandmother as daytime caring person might have a higher risk for ECC that those daytime cared by mother or school staff [14]. However, scientific literature is limited and controversial [14-16] regarding the association between childcare by a grandmother and risk for ECC.

Therefore, this retrospective study aimed to investigate the association between child's daytime caring person and risk for higher ECC experience.

\section{Material and Methods}

Sample Collection

This retrospective university-based study was conducted at the Baby Clinic of the School of Dentistry, Federal University of Rio Grande do Sul, Brazil. The convenience sample comprised of children (O-3 years old) treated during the period 2014-2018 by fourth and fifth-year undergraduate dental students, supervised by professors (pediatric dentistry specialists). To be eligible for the study, clinical records should have registered the child's daytime caring person and caries data based on clinical examination. Records with incomplete data, patients with special needs and children with compromised systemic health were excluded from the study.

In a total of 454 clinical records, 417 of them reported the child's daytime caring person. Ninety-four records presented incomplete data about caries experience and other 13 were of the children with health problems, hence, were excluded from the study. Thus, 310 children were included in the study. 


\section{Data Collection}

Two trained reviewers collected the information from clinical records. The factors potentially associated with ECC were investigated, including individual and clinical characteristics: child's gender (boys/girls), daytime caregiver schooling ( $\leq 8$ years/ $>8$ years of formal education), child's daytime caring person (mother/grandmother/others), cariogenic dietary - frequency of cariogenic dietary carbohydrate, mainly sugar intake, more than four times a day (yes/no), exclusive breastfeeding for 6 months (yes/no), breastfeeding duration ( $\leq 9$ months or $>9$ months), nocturnal feeding (yes/no), actual feeding (bottle, breastfeeding or both), sugar between main meals (yes/no), sugared milk (yes/no), toothbrushing frequency (once a day or twice or more times), and flossing use (yes/no). Caries experience (dmft index) of the patients at the first appointment was categorized using the median as the cutoff point. The child's age was a continuous variable (expressed in months).

\section{Data Analysis}

The compilation, organization, and codification of the data were performed using Microsoft Excel (Microsoft Corp., Seattle, USA). The statistical analyses were performed using SPSS software (SPSS Inc., version 22, Chicago, IL, USA). The response variable (caries experience) was dichotomized as $\mathrm{dmft} \leq 2 \mathrm{or}$ $\mathrm{dmft}>2$. Initially, bivariate analyses (chi-square test) were performed to investigate the associated factors with caries experience. A multiple regression model was created with crude and adjusted odds ratio (OR) estimates for caries experience according to the categories of the independent variables that were statistically significant in the bivariate analysis. Covariables with a p-value $<0.25$ in the univariate logistic regression analysis were incorporated into the multiple model, and Wald's backward method was used for the selection of variables for the model. Only covariables with a p-value $<0.05$ remained in the final model. The Hosmer and Lemeshow test was used to determine the goodness of fit of the final model. The level of significance was set at $5 \%$.

\section{Ethical Aspects}

The local Research Ethics Committee approved the research protocol (CAAE: 090401 12.5.0000.5347). The personal information of the patients was kept confidential.

\section{Results}

The sample was comprised of 310 children (146 boys and 154 girls) with an average age of 25.4 months $( \pm 8.4$ months), with a dmft index mean of 3.2 ( \pm 3.8 ). Additionally, $60.3 \%$ of them were active-caries, presenting an average of $5.2( \pm 7.5)$ active carious lesions.

Bivariate analyses results are shown in Table 1. There was no association between child's daytime caring person and caries experience $(\mathrm{p}=0.32)$. On the other hand, infants that had exclusive breastfeeding for 6 months $(\mathrm{p}<0.01)$ and were breastfed for more than 9 months $(\mathrm{p}<0.01)$ presented lower caries experience $(\mathrm{dmft} \leq 2)$. Toddlers that did not have a cariogenic diet $(\mathrm{p}<0.01)$ and did not consume sugar between main meals $(\mathrm{p}<0.01)$ also presented a minor caries experience. Moreover, low daytime caregiver schooling impacted on higher caries experience in early childhood $(\mathrm{p}<0.01)$. 
Table 1. Bivariate analyses results.

\begin{tabular}{|c|c|c|c|}
\hline Variables & $\begin{array}{c}\text { dmft } \leq 2 \\
N(\%)\end{array}$ & $\begin{array}{c}\text { dmft > } 2 \\
N(\%)\end{array}$ & p-value \\
\hline \multicolumn{4}{|l|}{ Daytime Caregiver Schooling } \\
\hline Up to Eight Years of Formal Education & $66(44.9)$ & $81(55.1)$ & $<0.01$ \\
\hline More Than Eight Years & $99(60.7)$ & $64(39.3)$ & \\
\hline \multicolumn{4}{|l|}{ Child's Daytime Caring Person } \\
\hline Mother & $85(56.3)$ & $66(43.7)$ & 0.32 \\
\hline Grandmother & $33(55.9)$ & $26(44.1)$ & \\
\hline Others & $47(47.0)$ & $53(53.0)$ & \\
\hline \multicolumn{4}{|l|}{ Cariogenic Dietary } \\
\hline Yes & $100(47.3)$ & $119(52.7)$ & $<0.01$ \\
\hline No & $58(69.0)$ & $26(31.0)$ & \\
\hline \multicolumn{4}{|l|}{ Child's Gender } \\
\hline Boys & $89(56.0)$ & $70(44.0)$ & 0.32 \\
\hline Girls & $76(50.3)$ & $75(49.7)$ & \\
\hline \multicolumn{4}{|l|}{ Exclusive Breastfeeding } \\
\hline Yes & $92(45.5)$ & $110(54.5)$ & $<0.01$ \\
\hline No & $73(67.6)$ & $35(32.4)$ & \\
\hline \multicolumn{4}{|l|}{ Actual Feeding } \\
\hline Breastfeeding & $37(52.9)$ & $33(47.1)$ & 0.18 \\
\hline Bottle Feeding & $88(57.9)$ & $64(42.1)$ & \\
\hline Both & $40(45.5)$ & $48(54.5)$ & \\
\hline \multicolumn{4}{|l|}{ Breastfeeding Duration } \\
\hline$\leq 9$ Months & $66(41.5)$ & $93(58.3)$ & $<0.01$ \\
\hline$>9$ Months & $99(65.6)$ & $52(34.4)$ & \\
\hline \multicolumn{4}{|l|}{ Nocturnal Feeding } \\
\hline Yes & $97(49.5)$ & $99(50.5)$ & 0.08 \\
\hline No & $68(59.6)$ & $46(40.4)$ & \\
\hline \multicolumn{4}{|l|}{ Sugar Between Main Meals } \\
\hline Yes & $94(45.2)$ & $114(54.8)$ & $<0.01$ \\
\hline No & $71(69.6)$ & $31(30.4)$ & \\
\hline \multicolumn{4}{|l|}{ Sugared Milk } \\
\hline Yes & $112(51.6)$ & $105(48.4)$ & 0.37 \\
\hline No & $53(57.0)$ & $40(43.0)$ & \\
\hline \multicolumn{4}{|l|}{ Toothbrushing Frequency } \\
\hline Once a Day & $105(58.0)$ & $76(42.0)$ & 0.05 \\
\hline Two Times a Day or More & $60(46.5)$ & $69(53.5)$ & \\
\hline \multicolumn{4}{|l|}{ Flossing Use } \\
\hline Yes & $12(48.0)$ & $13(52.0)$ & 0.58 \\
\hline No & $153(53.7)$ & $132(46.3)$ & \\
\hline
\end{tabular}

Logistic regression results for association between independent variables and caries experience are summarized in Table 2. The adjusted model showed that children with daytime caregiver presenting low education level had 5.76 times more chance of have higher caries experience in childhood $(\mathrm{p}=0.02)$. Breastfed infants for more than 9 months had less chance of have higher caries experience (OR: 0.38 95\%CI 0.21-0.68; $\mathrm{p}=0.00)$. The consumption of sugar between main meals increased the risk for caries $(\mathrm{p}=0.02)$. Children who did not receive nocturnal feeding had less chance of experiencing more caries in childhood (OR: 0.50, 95\% CI: 0.27-0.91; $\mathrm{p}=0.02)$. Moreover, higher caries experience was associated with older children $(\mathrm{p}=0.00)$. 
Table 2. Logistic regression for association between independent variables and caries experience in early childhood.

\begin{tabular}{|c|c|c|c|c|}
\hline Variables & Crude OR (95\% CI) & p-value & $\begin{array}{c}\text { Adjusted OR } \\
(95 \% \mathrm{CI})\end{array}$ & p-value \\
\hline \multicolumn{5}{|l|}{ Daytime Caregiver Schooling } \\
\hline More Than Eight Years & 1 & 0.03 & 1 & 0.02 \\
\hline Up to Eight Years of Formal Education & $5.91(1.16-30.10)$ & & $5.76(1.18-28.18)$ & \\
\hline \multicolumn{5}{|l|}{ Cariogenic Dietary } \\
\hline No & 1 & 0.39 & & \\
\hline Yes & $1.35(0.68-2.70)$ & & & \\
\hline \multicolumn{5}{|l|}{ Exclusive Breastfeeding } \\
\hline No & 1 & 0.37 & & \\
\hline Yes & $0.74(0.38-1.43)$ & & & \\
\hline \multicolumn{5}{|l|}{ Feeding } \\
\hline Breastfeeding & 1 & & & \\
\hline Bottle Feeding & $0.89(0.41-1.97)$ & 0.78 & & \\
\hline Both & $1.38(0.50-3.75)$ & 0.53 & & \\
\hline \multicolumn{5}{|l|}{ Breastfeeding Duration } \\
\hline$\leq 9$ Months & 1 & 0.02 & 1 & 0.00 \\
\hline > 9 Months & $0.33(0.13-0.83)$ & & $0.38(0.21-0.68)$ & \\
\hline \multicolumn{5}{|l|}{ Nocturnal Feeding } \\
\hline Yes & 1 & 0.04 & 1 & 0.02 \\
\hline No & $0.51(0.27-0.96)$ & & $0.50(0.27-0.91)$ & \\
\hline \multicolumn{5}{|l|}{ Sugar Between Main Meals } \\
\hline Yes & 1 & 0.07 & 1 & 0.02 \\
\hline No & $0.56(0.30-1.04)$ & & $0.50(0.28-0.89)$ & \\
\hline \multicolumn{5}{|l|}{ Toothbrushing Frequency } \\
\hline Once a Day & 1 & 0.49 & & \\
\hline Two Times a Day or More & $0.82(0.47-1.44)$ & & & \\
\hline Child's Age & $1.13(1.08-1.18)$ & 0.00 & $1.14(1.09-1.19)$ & 0.00 \\
\hline
\end{tabular}

\section{Discussion}

This retrospective university-based study provides information if child's daytime caring person is a risk for higher ECC experience. In this study, the variable "caregiver" was categorized as follows: mother, grandmother or others (e.g., other family members, baby-sitter or school staff). There was no association between child's daytime caring person and caries experience in early childhood.

Food treats play an important role in the grandparent-grandchild relationship and are used by grandparents to differentiate their identity and relationship from parents and other family members [17]. It has been speculated that grandparents indulge grandchildren with foods and drinks, generally in the form of discretionary choices (e.g., those high in sugar, fat and/or sodium) [18], which may lead a higher caries risk. Negative reports about grandparental feeding practices, however, are mainly from parental perceptions. On the other hand, a recent study [19] showed that grandparents favored core-food over discretionary-food treats. They considered the risks (e.g., dental caries) and rewards (e.g., pleasure) of food treats and balanced their wishes with those of their grandchildren and parents [19].

A previous study [20] showed that the percentage of caries experience was higher among children living with grandparents than children living without grandparents. However, the association between grandparent co-residence and dental caries was confounded by socioeconomics factors. The low caregiver education and low household income contributed to the reduced prevalence of parental control over toothbrushing frequency and daily sugar-sweetened beverage intake, increasing the caries risk. 
Since the bivariate analysis showed that the child's daytime caring person did not influence on caries experience, we performed the multiple regression analysis to investigate the risk factors associated with ECC. Low daytime caregiver education was associated with higher caries experience in childhood. Caregivers well educated may have high dental knowledge levels, which might explain the better oral health of their children.

Breastfed infants for more than 9 months and who did not receive nocturnal feeding had less chance of experiencing more caries in childhood. It has been evidenced that breastfeeding is more effective at preventing dental caries in early childhood than bottle feeding [21]. Children who were breastfed for longer than 12 months have fewer dental caries than those exposed to breastfeeding for a shorter time [22]. Additionally, nocturnal breastfeeding longer than 12 months is associated to increase in prevalence of dental caries in children [22].

There are many dietary factors associated with ECC. Most of these factors are related either to the frequency, amount, or timing of sugar consumption [23]. The frequency sugar intake 3 times per day was found as an increased risk for ECC [24]. In this study, frequency of sugar intake more than four times a day was considered as cariogenic dietary. In the bivariate analysis, dietary cariogenic was associated with higher caries experience. However, its association lost significance in the regression analysis. Conversely, the consumption of sugar between main meals increased the caries risk. Caries risk also increased with age, in line with previous studies $[11,25,26]$. It may be related to the accumulation of socio-biological risks that continuously act with advancing age. This study's results should be viewed with caution for their methodological limitations. The retrospective aspect may introduce selection bias and mis-classification or information bias. With retrospective studies, it is not possible to control the exposure or outcome assessment, and instead must rely on others for accurate record keeping. Moreover, the temporal relationship is frequently difficult to assess [27].

It is important to highlight that only $19 \%$ of children had the grandmother as daytime caring person and most of them $(48.7 \%)$ were cared by mothers. The description of a risk factor clearly indicates that the exposure has occurred prior to the outcome. Hence, prospective longitudinal studies are needed to elucidate risk factors for ECC, such as the child's daytime caring person.

\section{Conclusion}

A higher caries experience in early childhood is not associated to child's daytime caring person. On the other hand, the higher caries experience is associated with low caregiver schooling and older children.

\section{Authors' Contributions}

\begin{tabular}{|c|c|c|}
\hline BTP & (iD) 0000-0003-1459-1115 & $\begin{array}{l}\text { Conceptualization, Methodology, Investigation and Writing - Original Draft } \\
\text { Preparation. }\end{array}$ \\
\hline DP & (iD) $0000-0003-1717-9097$ & Methodology. \\
\hline CMS & (iD) $0000-0003-0924-328 \mathrm{X}$ & Conceptualization and Writing - Review and Editing. \\
\hline $\mathrm{FMF}$ & (iD) $0000-0001-9400-1167$ & Formal analysis and Writing - Review and Editing. \\
\hline $\mathrm{MFC}$ & (iD) $0000-0002-4279-5417$ & Writing - Review and Editing. \\
\hline TLL & (iD 0000-0003-3568-5217 & Conceptualization and Writing - Original Draft Preparation. \\
\hline
\end{tabular}

\section{Financial Support}

None. 


\section{Conflict of Interest}

The authors declare no conflicts of interest.

\section{References}

[1] American Academy on Pediatric Dentistry. American Academy of Pediatrics. Policy on early childhood caries (ECC): classifications, consequences, and preventive strategies. Pediatr Dent 2016;30(7):40-3.

[2] Tinanoff N, Baez RJ, Guillory CD, Donly KJ, Feldens CA, McGrath C, et al. Early childhood caries epidemiology, aetiology, risk assessment, societal burden, management, education, and policy: global perspective. Int J Paediatr Dent 2019; 29(3):238-48. https://doi.org/10.1111/ipd.12484

[3] Ortiz FR, Tomazoni F, Oliveira MDM, Piovesan C, Mendes F, Ardenghi TM. Toothache, associated factors, and its impact on Oral health-related quality of life (OHRQoL) in preschool children. Braz Dent J 2014; 25(6):546-53. https://doi.org/10.1590/0103-6440201302439

[4] Corrêa-Faria P, Daher A, Freire MCM, Abreu MHNG, Bönecker M, Costa LR. Impact of untreated dental caries severity on the quality of life of preschool children and their families: a cross-sectional study. Qual Life Res 2018; 27(12):3191-8. https://doi.org/10.1007/s1 1136-018-1966-5

[5] Buldur B. Pathways between parental and individual determinants of dental caries and dental visit behaviour among children: Validation of a new conceptual model. Community Dent Oral Epidemiol 2020; 48(4):280-7. https://doi.org/10.1111/cdoe.12530

[6] Fejerskov O. Changing paradigms in concepts on dental caries: Consequences for oral health care. Caries Res 2004; 38(3):182-91. https://doi.org/10.1159/000077753

[7] Peres KG, Chaffee BW, Feldens CA, Flores-Mir C, Moynihan P, Rugg-Gunn A. Breastfeeding and oral health: Evidence and methodological challenges. J Dent Res 2018; 97(3):251-8. https://doi.org/10.1177/0022034517738925

[8] Chaffee BW, Feldens CA, Rodrigues PH, Vítolo MR. Feeding practices in infancy associated with caries incidence in early childhood. Community Dent Oral Epidemiol 2015; 43(4):338-48. https://doi.org/10.1111/cdoe.12158

[9] Buldur B, Güvendi ON. Conceptual modelling of the factors affecting oral health-related quality of life in children: a path analysis. Int J Paediatr Dent 2020; 30(2):181-92. https://doi.org/10.1111/ipd.12583

[10] Qiu RM, Lo ECM, Zhi QH, Zhou Y, Tao Y, Lin HC. Factors related to children's caries: a structural equation modeling approach. BMC Public Health 2014; 14:1071. https://doi.org/10.1186/1471-2458-14-1071

[11] Melo MMDC, Souza WV, Lima MLC, Braga C. Factors associated with dental caries in preschoolers in Recife, Pernambuco State, Brazil. Cad Saude Publica 2011; 27(3):471-85. https://doi.org/10.1590/s0102-311x2011000300008

[12] Hayslip Jr B, Kaminski PL. Grandparents raising their grandchildren: a review of the literature and suggestions for practice. Gerontologist 2005; 45(2):262-9. https://doi.org/10.1093/geront/45.2.262

[13] Farrow C. A comparison between the feeding practices of parents and grandparents. Eat Behav 2014; 15(3):339-42. https://doi.org/10.1016/j.eatbeh.2014.04.006

[14] Ohsuka K, Chino N, Nakagaki H, Kataoka I, Oshida Y, Ohsawa I, et al. Analysis of risk factors for dental caries in infants: A comparison between urban and rural areas. Environ Health Prev Med 2009; 14(2):103-10. https://doi.org/10.1007/s12199-008-0065-6

[15] Mizoguchi K, Kurumado K, Tango T, Minowa M. Study on factors for caries and infant feeding characteristics in children aged 1.5-3 years in a Kanto urban area. Nihon Koshu Eisei Zasshi 2003; 50(9):867-78.

[16] Mitoh S. Lifestyle factors affecting prevalence of dental caries in infants in Onomichi-city. J Dent Health 2006; 56(5):688-708. https://doi.org/10.5834/jdh.56.5_688

[17] Smorti M, Tschiesner R, Farneti A. Grandparents-grandchildren relationship. Procedia - Social Behav Sci 2012; 46:895-8. https://doi.org/10.1016/j.sbspro.2012.05.219

[18] Eli K, Howell K, Fisher PA, Nowicka P. A question of balance: explaining differences between parental and grandparental perspectives on preschoolers' feeding and physical activity. Soc Sci Med 2016; 154:28-35. https://doi.org/10.1016/j.socscimed.2016.02.030

[19] Pankhurst M, Mehta K, Matwiejczyk L, Moores CJ, Prichard I, Mortimer S, et al. Treats are a tool of the trade: an exploration of food treats among grandparents who provide informal childcare. Public Health Nutr 2019; 22(14):2643-52. https://doi.org/10.1017/s1368980019000685

[20] Morita A, Matsuyama Y, Isumi A, Doi S, Ochi M, Fujiwara T. Association between grandparent co-residence, socioeconomic status and dental caries among early school-aged children in Japan: a population-based prospective study. Sci Rep 2019; 9(1):11345. https://doi.org/10.1038/s41598-019-47730-3

[21] Avila WM, Pordeus IA, Paiva SM, Martins CC. Breast and bottle feeding as risk factors for dental caries: a systematic review and meta-analysis. PLoS One; 10(11):e0142922. https://doi.org/10.1371/journal.pone.0142922

[22] Tham R, Bowatte G, Dharmage SC, Tan DJ, Lau MXJ, Dai X, et al. Breastfeeding and the risk of dental caries: a systematic review and meta-analysis. Acta Paediatr 2015; 104(467):62-84. https://doi.org/10.1111/apa.13118

[23] Kirthiga M, Murugan M, Saikia A, Kirubakaran R. Risk Factors for early childhood caries: a systematic review and meta-analysis of case control and cohort studies. Pediatr Dent 2019; 41(2):95-112. 
[24] Watanabe M, Wang D, Ijichi A, Shirai C, Zou Y, Kubo M, et al. The Influence of lifestyle on the incidence of dental caries among 3-year-old Japanese children. Int J Environ Res Public Health 2014; 11(12):12611-22. https://doi.org/10.3390/ijerph111212611

[25] Dini EL, Holt RD, Bedi R. Caries and its association with infant feeding and oral health-related behaviours in 3-4year-old Brazilian children. Community Dent Oral Epidemiol 2000; 28(4):241-8. https://doi.org/10.1034/j.1600-0528.2000.280401.x

[26] Oliveira LB, Sheiham A, Bönecker M. Exploring the association of dental caries with social factors and nutritional status in Brazilian preschool children. Eur J Oral Sci 2008; 116(1):3743. https://doi.org/10.1111/j.1600-0722.2007.00507.x

[27] Thiese MS. Observational and interventional study design types; an overview. Biochem Med 2014; 24(2):199-210. https://doi.org/10.11613/bm.2014.022 